\title{
ANÁLISE DE ATRIBUTOS QUÍMICOS DO SOLO EM ÁREAS CULTIVADAS COM GRÃOS NO NORDESTE PARAENSE, UTILIZANDO AGRICULTURA DE PRECISÃO
}

\author{
Shirlene Souza Oliveira ${ }^{1}$; Deymeson Mateus Soares da Silva ${ }^{2}$; Lucilene Rodrigues dos \\ Santos $^{3}$; Danielly Cristina da Silva Marques ${ }^{4}$; Jose Leandro Silva de Araújo ${ }^{5}$; Eduardo \\ Cézar Medeiros Saldanha ${ }^{6}$. \\ ${ }^{1}$ Graduando do Curso de Agronomia da Universidade Federal Rural da Amazônia, Campus Capitão Poço. \\ Capitão Poço, Pará, Brasil. oliveira.shirlene2010@gmail.com \\ ${ }^{2}$ Graduando do Curso de Agronomia da Universidade Federal Rural da Amazônia, Campus Capitão \\ Poço. Capitão Poço, Pará, Brasil \\ ${ }^{3}$ Professor, Mestre da Universidade Federal Rural da Amazônia, Campus Capitão Poço. Capitão Poço, Pará, \\ Brasil. eduardo.saldanha@ufra.edu.br.
}

\begin{abstract}
RESUMO: As aplicações de técnicas de agricultura de precisão no manejo da fertilidade do solo tem otimizado o uso de adubos possibilitando maior sustentabilidade dos sistemas agrícolas. Objetivou-se neste trabalho avaliar a variabilidade temporal de alguns atributos químicos do solo sob cultivo de grãos no município de Paragominas - PA, por meio do uso de técnicas de agricultura de precisão. O estudo foi desenvolvido em 17 propriedades agrícolas, nos anos de 2009 e 2010, mensurando resultados de 1.945 amostras de solos. Os solos cultivados com grãos apresentaram baixa acidez, saturação por base abaixo de $50 \%$. A fertilidade do solo avaliada pelos resultados obtidos é de média a alta.
\end{abstract}

PALAVRAS-CHAVE: adubação, fertilidade, manejo.

\section{ATTRIBUTES OF CHEMICAL ANALYSIS OF CULTIVATED LAND IN AREAS WITH GRAINS IN NORTHEAST PARAENSE USING PRECISION FARMING}

\begin{abstract}
The applications of precision agriculture techniques in the management of soil fertility has optimized the use of fertilizers enabling more sustainable agricultural systems. The objective of this study was to evaluate the temporal variability of some soil chemical properties under grain cultivation in the municipality of Paragominas - PA, through the use of precision agriculture techniques. The study was conducted on 17 farms in the years 2009 and 2010, measuring results of 1945 soil samples. The soils cultivated with grains had low acidity, base saturation below $50 \%$. Soil fertility is evaluated by the results obtained from medium to high.
\end{abstract}

KEY-WORDS: fertilization, fertility, management.

\section{INTRODUÇÃO}

O município de Paragominas, situado na mesorregião sudeste do Pará, a 320 km da cidade de Belém, possui uma área de 1,93 milhões de hectares e abriga uma população de 97.819 mil habitantes (IBGE, 
2010). Concentra a maioria das atividades econômicas desenvolvidas na região amazônica, a saber: criação de gado bovino, exploração de madeira, manejo florestal, reflorestamento, cultivo de soja (e outros grãos) e mineração de bauxita.

Aproveitando a abundância de suas áreas já abertas e planas e com um regime pluviométrico bem definido, essas culturas têm apresentado excelentes desempenhos em produção por área, colocando Paragominas entre os maiores produtores de grãos do Pará. O cultivo de grãos como arroz (Oryza sativa L.), milho (Zea mays) e soja (Glycine max) em Paragominas ocupa aproximadamente 35 mil hectares (PINTO et al., 2009).

Os solos da região apresentam grande variabilidade espacial dos atributos, cuja fertilidade natural é baixa, com predomínio dos Latossolos Amarelo distróficos, que cobrem $95 \%$ do território municipal. Para solos com baixa fertilidade e variabilidade nos atributos, a agricultura de precisão, cujo objetivo consiste em aumentar a eficiência, com base no manejo diferenciado de áreas na agricultura, constitui-se em uma ferramenta indispensável à otimização de insumos e melhor gerenciamento do sistema produtivo. Com isso, a aplicação de técnicas de agricultura de precisão no manejo da fertilidade do solo tem despertado o interesse de agricultores, consultores e empresas prestadoras de serviços.

O objetivo deste trabalho, foi avaliar a variabilidade temporal de alguns atributos químicos do solo sob cultivo de grãos no município de Paragominas, Estado do Pará, através do uso de técnicas de agricultura de precisão.

\section{MATERIAL E MÉTODOS}

O estudo foi realizado em 17 propriedades agrícolas do município de Paragominas, que cultivam grãos (arroz, soja e milho) em cultivos alternados por um período médio de aproximadamente 12 anos. O município de Paragominas está localizado no quadrante com coordenadas geográficas $2^{\circ} 39^{\prime}$ e $3^{\circ} 40^{\prime}$ de latitude Sul e os meridianos de $46^{\circ} 27^{\prime}$ e $48^{\circ} 50^{\prime}$ de longitude a oeste de Greenwich. Conforme a classificação de Köppen, o clima da região é do tipo Awi, o que corresponde a um clima tropical chuvoso com estação seca bem definida. (BASTOS et al., 2005).

Para o estudo utilizou-se um banco de dados com resultados de amostras de solos coletadas nos anos de 2009 e 2010. A amostragem do solo foi realizada em uma área total de aproximadamente 9.725 ha, com grade amostral de 5 ha, perfazendo o total de 1.945 pontos amostrais (amostras compostas). Cada amostra composta foi 
georreferenciada e formada a partir de 10 amostras simples coletadas em um círculo ao redor de cada grade de amostragem.

As coletas de solo foram realizadas com auxílio de um trado de rosca de aço inoxidável automatizado com motor elétrico, instalado em um quadricíclo equipado com um aparelho de GPS, na profundidade de $0-0,2 \mathrm{~m}$, sendo posteriormente armazenadas e enviadas para análise química em laboratório especializado.

$\mathrm{O} \mathrm{pH}$ foi determinado utilizando-se relação 1:2,5 de solo: água. A partir dos resultados do complexo sortivo, foram calculados os valores de capacidade de troca catiônica total $(\mathrm{T})$ e saturação por bases (V). Os resultados foram submetidos à análise estatística descritiva dos dados, por meio do software estatístico SISVAR (2013). A variabilidade dos atributos classificada em baixa $(\mathrm{CV}<12 \%)$, média $(12 \leq \mathrm{CV} \geq 62 \%)$ e alta $(\mathrm{CV}>62 \%)$ e interpretadas com base nos teores e limites críticos reportados por Raij et al. (1996) e CFSEMG (1999).

\section{RESULTADOS E DISCUSSÃO}

As análises químicas nas 17 propriedades produtoras de grãos georeferenciadas da área em estudo são apresentadas na Tabela 1 .

Tabela 1. Estatística descritiva dos valores de $\mathrm{pH}$, saturação por bases (V) e capacidade de troca de cátions (CTC T). Valores médios (Md), medianos (Med), mínimo (Min), máximo (Max), desvio padrão (s), coeficiente de variação $(\mathrm{CV})$, variância $\left(\mathrm{s}^{2}\right)$, coeficiente de curtose (Curt), coeficiente de assimetria (Assim), de 1.945 amostras no período de 2009 e 2010.

\begin{tabular}{lccccccccc}
\hline Variável & Md & Med & Min & Max & s & CV & S $^{2}$ & Curt & Assim \\
\hline $\mathrm{H}\left(\mathrm{H}_{2} \mathrm{O}\right)$ & 5,7 & 5,7 & 4,5 & 8 & 0,4 & 7,7 & 0,2 & 1,6 & 0,3 \\
$\mathrm{~V}(\%)$ & 47 & 46,7 & 10 & 94,8 & 13,6 & 28,9 & 185 & 0,1 & 0,3 \\
$\mathrm{CTC} \mathrm{T}\left(\mathrm{cmol}_{\mathrm{c}} \mathrm{dm}^{-3}\right)$ & 7,89 & 7,9 & 2,6 & 15,2 & 1,64 & 20,78 & 2,71 & 1,06 & 0,05 \\
\hline
\end{tabular}

De acordo com as informações relatadas por Raij et al. (1996) e CFSEMG (1999) Tabela 2, os resultados descritos indicam existir níveis que variam de muito baixo à alto, caso do pH, V (\%) e CTC, respectivamente. Os níveis adequados de
$\mathrm{pH}$ e indicadores de acidez do solo, provavelmente, são decorrentes da aplicação de corretivos e fertilizantes nas áreas de cultivo, ao longo de aproximadamente 12 anos. 
Tabela 2. Níveis de fertilidade do Solo para interpretação dos resultados.

\begin{tabular}{lcccccc}
\hline Atributo químico & Unidade & \multicolumn{5}{c}{ Classificação } \\
\hline & & Muito baixo & Baixo & Média & Alto & Muito alto \\
\cline { 2 - 7 } $\mathrm{pH}$ & & $<4,5$ & $4,5-5,40$ & $5,41-6,0$ & $6,1-7,0$ & $>7,0$ \\
$\mathrm{CTC}$ T & $\mathrm{cmol}_{\mathrm{c} .} \mathrm{dm}^{-3}$ & $\leq 1,60$ & $1,61-4,30$ & $4,31-8,60$ & $8,61-15$ & $>15$ \\
Saturação por bases & $\%$ & $\leq 20$ & $21-40$ & $41-60$ & $61-80$ & $>80$ \\
\hline Fonte: Adaptado de UFV (1999) e Raij et al. (1996). & & & &
\end{tabular}

Por meio da análise da Figura 1 verifica-se que $52 \%$ das amostras coletadas apresentaram acidez média com base na classificação de Raij et al. (1996) e CFSEMG (1999) que varia de 5,5 a 6,0, ou seja, a maioria dos solos amostrados no trabalho encontra-se com o $\mathrm{pH}$ próximo ao agronomicamente ideal, corroborando com os dados relatados por El-Husny et al.
(2006). O benefício da calagem foi descrito por Morais e Albuquerque (2006), que constataram efeitos significativos das doses de calcário na elevação dos valores de $\mathrm{pH}$, na camada arável de $0-0,20 \mathrm{~m}$ de profundidade, em Latossolo da região de Paragominas, PA. Com os valores de $\mathrm{pH}$ verifica-se que maioria das amostras de solo apresentaram valores médios.

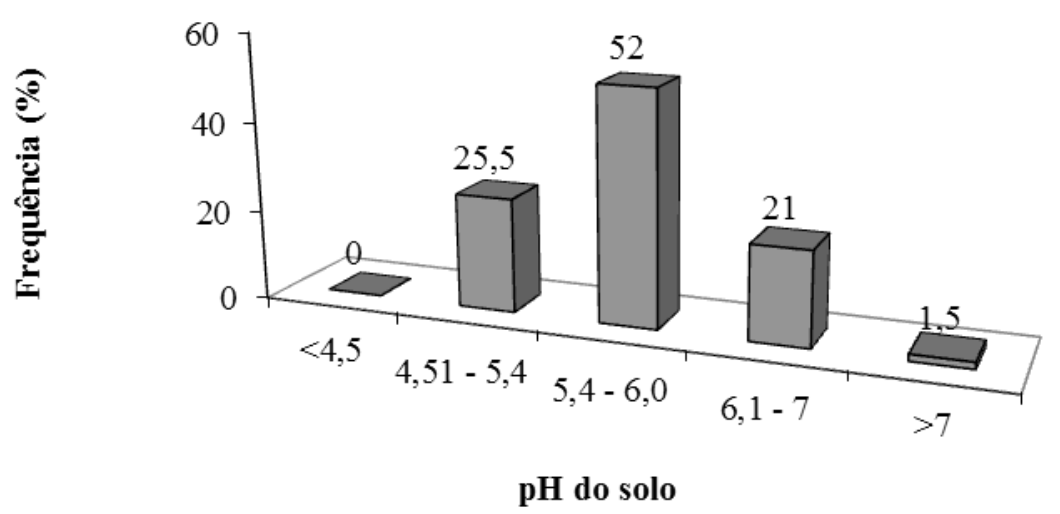

Figura 1. Distribuição de frequência de $\mathrm{pH}$ das amostras compostas de solos sob cultivo alternado no município de Paragominas - PA, entre os anos de 2009 e 2010.

Para saturação por bases (V\%) Figura 2, de acordo com Raij et al. (1996) e CFSEMG (1999) $52 \%$ dos locais amostrados apresentaram valores de $\mathrm{V} \%$ considerados médios, enquanto $15,7 \%$ foram caracterizados com altos níveis, o 
que favorece o desenvolvimento da planta, uma vez que para as culturas de grãos recomenda saturação por bases em torno de 40-50\% (FAGERIA, 2001).

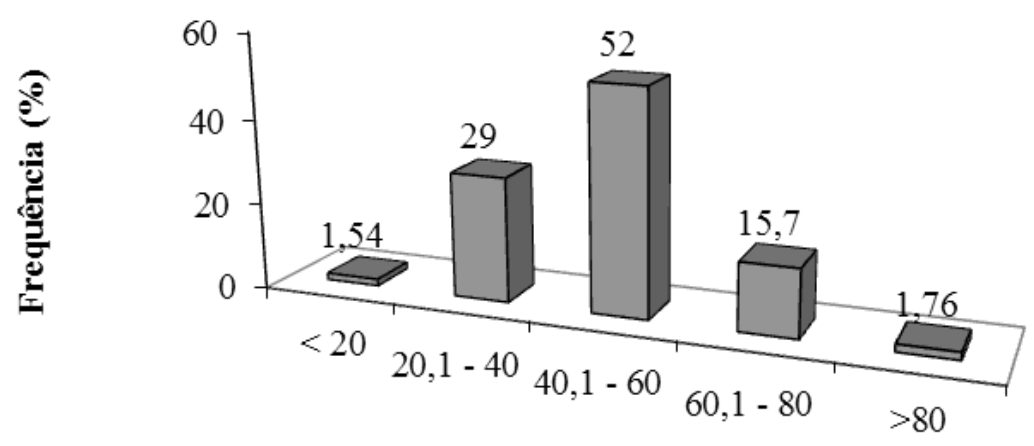

Saturação por bases (\%)

Figura 2. Distribuição de frequência da saturação por bases das amostras compostas de solos sob cultivo alternado no município de Paragominas - PA, entre os anos de 2009 e 2010.

Para a variável capacidade de troca de cátions (CTC), observa-se na Figura 3 que $66 \%$ das amostras apresentaram teores considerados médios e $30 \%$ teores considerados altos, possivelmente, esse efeito ocorreu em decorrência da presença de elevados valores de $\mathrm{pH}$ na região, o que contribui para a geração de carga elétricas negativas, com consequente elevação da CTC.

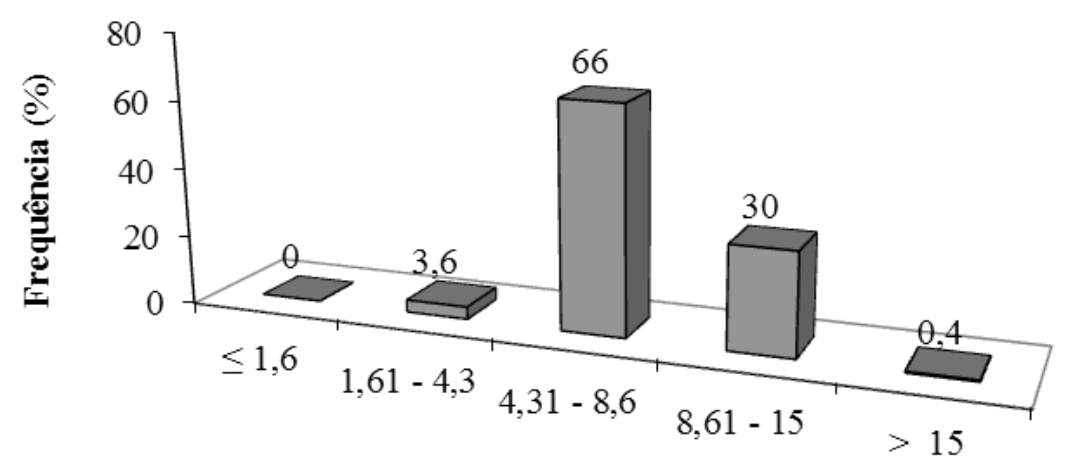

Capacidade de Troca de Cátions - CTC (cmolc dm-3)

Figura 3. Distribuição de frequência da Capacidade de Cátions - CTC das amostras compostas de solos sob cultivo alternado no município de Paragominas - PA, entre os anos de 2009 e 2010. 


\section{CONCLUSÕES}

Os atributos do solo analisados mostraram variação nos valores de $\mathrm{pH}$, saturação por base e capacidade de troca de cátions, em cultivos alternados de grãos, obtidos através da técnica da agricultura de precisão, apresentando, no geral, valores de fertilidade do solo de médio a alto.

\section{REFERÊNCIAS}

ALVAREZ, V.V. H.; NOVAIS, R. F.; BARROS, N. F.; CANTARUTTI, R. B.; LOPES, A. S. Interpretação dos resultados e analise do solo. In: RIBEIRO, A.C.; GUIMARAES, P.T.G.; ALVAREZ, V.V.H. (Ed). Recomendação para o uso de corretivos e fertilizantes em Minas Gerais: 5. Aproximação. Viçosa: Comissão de Fertilidade do Solo do Estado de Minas Gerais, 1999. p.25-32.

BASTOS, T. X et al. Características agroclimáticas do município de Paragominas. Belém: Embrapa Amazônia Oriental, 2005. 21p. (Documento, 228). Disponível em: < http://www.infoteca.cnptia.embrapa.br/h andle/doc/407905>. Acesso em: 10 maio 2013.

\section{EL-HUSNY, J.C. et al. Soja BRS} candeia: comportamento e recomendação para plantio nas microrregiões de Paragominas e Santarém, PA. Belém:
EMBRAPA-CPATU, $2006.5 p$.

(Comunicado Técnico, 182.)

FAGERIA, N.K. Resposta de arroz de terras altas, feijão, milho e soja à saturação por base em solo de cerrado. Revista Brasileira de Engenharia Agrícola e Ambiental, v. 5, n. 3, p. 416-424, 2001.

INSTITUTO BRASILEIRO DE GEOGRAFIA E ESTATÍSTICA. Banco de dados. Disponível em:< http://www.ibge.gov.br/home/geociencias/ default_prod.shtm>. Acesso em: 23 abr. 2010.

MORAIS, F.I.O; ALBUQUERQUE, R.N.O. Composição mineral da soja e propriedades químicas de um Latossolo Amarelo com pastagens degradadas de Paragominas em função da calagem e da adubação fosfatada. Revista Ciências Agrárias, n. 46, p. 89-105, 2006.

PINTO, Andréia. et al. Diagnóstico socioeconômico e florestal do município de Paragominas. Belém: Instituto do Homem e Meio Ambiente da Amazônia Imazon, 2009. 65p. Relatório Técnico.

SISVAR: a computer statistical analysis system, 2013. Sistema Computacional de Análise Estatística. 